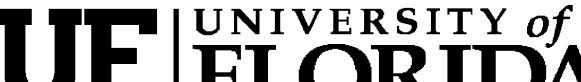 FLORIDA \\ IFAS Extension
}

\section{Professionalism and Pesticides: Public and Customer Communications ${ }^{1}$}

\section{Frederick M. Fishel ${ }^{2}$}

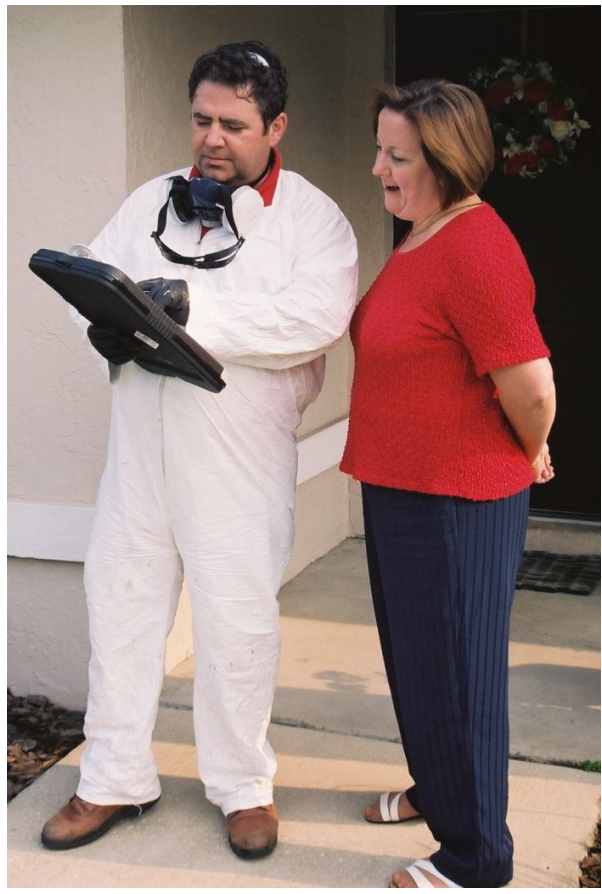

Figure 1. For a professional pesticide applicator, professionalism affects all aspects of conducting business.

The importance of professionalism to a successful business cannot be overstated. A professional person or company must strive for excellence. Professionalism deals not only with how you and your equipment look, but also how you deal with other employees, customers, the public, and, in some cases, the media (Figure 1). This can all be summed up as "your professional image."

\section{Components of Professionalism}

Professionalism includes continuing education, keeping up with current pesticide regulations, knowing enough to ask for outside help when you do not have all the answers, knowing the safety and environmental aspects of the job, and taking the initiative to communicate with your customers. What the public hears from the receptionist, technician, and pesticide applicator helps form their opinion of the company as much as do the final results of pesticide application.

\section{Learning the Lingo}

Creating a professional image begins with the vocabulary used by employees. When discussing pests and pesticides, use terminology the public can understand. Pesticide applicators must never give their customers or other members of the public the impression the pesticide products they use are "safe" or imply the products or services they offer are "safer" than those used by other companies.

1. This document is PI213, one of a series of the Agronomy Department, Florida Cooperative Extension Service, Institute of Food and Agricultural Sciences, University of Florida. Original publication date, January 2009. Visit the EDIS Web site at http://edis.ifas.ufl.edu.

2. Frederick M. Fishel, associate professor, Agronomy Department, and director, Pesticide Information Office; Florida Cooperative Extension Service, Institute of Food and Agricultural Sciences, University of Florida, Gainesville, FL 32611.

The Institute of Food and Agricultural Sciences (IFAS) is an Equal Opportunity Institution authorized to provide research, educational information and other services only to individuals and institutions that function with non-discrimination with respect to race, creed, color, religion, age, disability, sex, sexual orientation, marital status, national origin, political opinions or affiliations. U.S. Department of Agriculture, Cooperative Extension Service, University of Florida, IFAS, Florida A. \& M. University Cooperative Extension Program, and Boards of County Commissioners Cooperating. Interim Dean Millie Ferrer. 
Never use phrases such "environmentally friendly," "safe," "safe for children and pets," "safer," and "harmless" when referring to pesticide products or to the services offered by a pesticide applicator. Also, avoid using the terms "organic," "natural," or "least toxic" because these terms lack a common definition and are likely to confuse your customers. Pesticide applicators must not refer to EPA- and state-registered products as "EPA-approved" or

"state-approved." Such references can give the public the impression no risks are associated with the use of the pesticide products and these agencies endorse, approve, or recommend the use of particular products.

Acceptable terminology may include describing the product as "reduced risk" and/or "less toxic." Explain to the customer why the risk is reduced when compared with use of a higher toxicity product. Also explain whether the product requires more applications to be effective. Provide customers information packets that explain the risks associated with the pesticide (this may include additional information from labels or MSDS).

It is important for pesticide applicators and pest-management specialists to spend time with each customer, explaining what needs to be done and why. Customers should be informed about environmental, cultural, and physical factors that can contribute to ongoing pest problems. For example, moisture, humidity, planting site, sanitation, improper plant selection, and ineffective barriers all may play a role in pest outbreaks. Do not merely tell the customer what you are spraying for, but, rather, show the customer the problems.

Defining the what and why includes explaining product selection, how it is to be used, and anticipated results. Be factual and, above all, do not exaggerate the results your customer can expect from the treatment. Inform the customer about any post-application label instructions, such as reentry restrictions, watering in a pesticide, or livestock grazing or feeding prohibitions, whether in the field, the garden, or a structure (Figure 2).

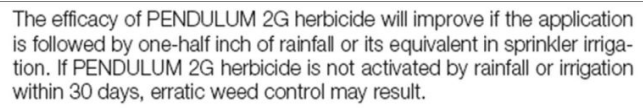

The efficacy of PENDULUM 2G herbicide will improve if the application is followed by one-half inch of rainfall or its equivalent in sprinkler irrigation. If PENDULUM $2 \mathrm{G}$ herbicide is not activated by rainfall or irrigation within 30 days, erratic weed control may result.

Figure 2. Inform your customer of post-application directions for products you apply.

\section{Florida-Specific Requirements for Professional Applicators}

Some states, including Florida, have mandatory preapplication notification requirements for customers or neighbors. These include chemical hypersensitivity registries currently enforced. Be sure to let your customers know if the neighbors have requested notification and if they have any concerns or objections involving the use of pesticides. At a minimum, prior notification to concerned individuals should include:

- Date and address of the scheduled application;

- Name and telephone number of the applicator;

- The type of pesticide that will be used; and,

- The applicator's certification/license number, where applicable.

More information on notification requirements may be found at http://edis.ifas.ufl.edu/PI004.

Florida law requires pesticide applicators to post notices of pesticide applications they make to lawns and exterior foliage (ornamental plantings) when these are part of the landscape around a building (Figure 3). This requirement is in the Florida Structural Pest Control Law (Chapter 482 F.S.), which is administered by the Bureau of Entomology and Pest Control of the Florida Department of Agriculture and Consumer Services (FDACS). 


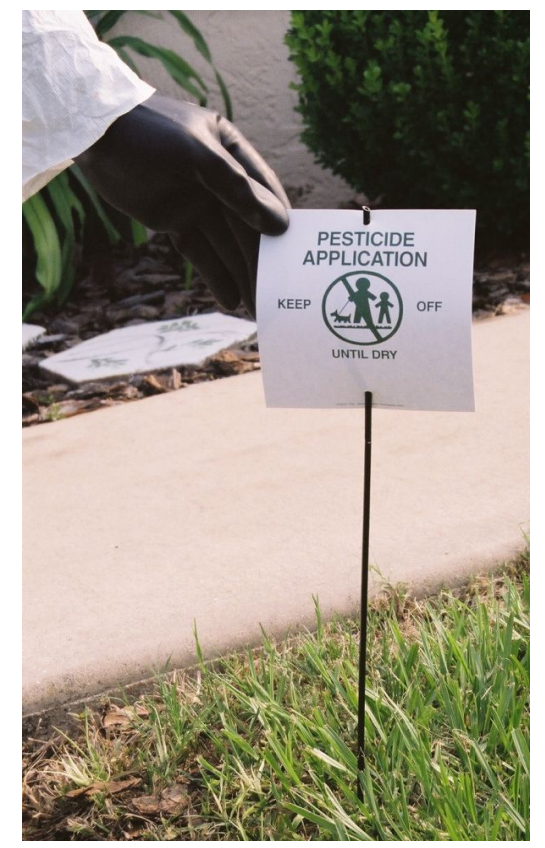

Figure 3. Notice of application of pesticides to a lawn.

\section{Pesticide Records}

To maintain good customer and public communications, consider keeping more detailed records than required by law. Records can prove invaluable as documentation in the event of a complaint or a lawsuit against your business. Pesticide records provide all the necessary information about the pesticides and how they were applied, thus protecting the applicator from what may be false accusations. Additional information that could be valuable to include in your records include the following: weather, nozzle sizes, spray pressures, ground speed, calibration, or any other special precautions that may have been used or taken. Records can also help determine which pesticide treatments work, which treatments do not work, and why.

Recordkeeping is also a major tool of IPM, including documenting pest sightings and population levels, pest-control techniques used, and overall environmental conditions. Good records enable an applicator to make more informed pest-control decisions. If medical treatment for a pesticide injury is required for humans or animals, records can provide information necessary to the medical staff for diagnosis and treatment. Good records can also document the steps that were taken to protect workers and the environment from pesticides. Records may also be used to respond to the public's concern regarding pesticide use.

More details on Florida's requirement for pesticide records may be viewed at http://edis.ifas.ufl.edu/PI012.

\section{Answering Your Customers Questions}

Today, customers and other concerned individuals are likely to ask the pesticide applicator, the sales representative, or the service technician about the products that will be used to manage their pest problems. Customers may ask about possible effects on children, pets, property, the environment, and on themselves. How you answer these questions can determine whether your customer is satisfied. Preparing yourself and your staff to answer consumer concerns is the professional approach. A good way to familiarize every pesticide applicator and technician in the company with typical questions and answers is to discuss these during company training sessions. Role playing by staff members can help reinforce correct and responsible responses.

If requested by the customer or anyone else inquiring about pesticides, provide Web addresses and 800 phone numbers for pesticide emergencies and information. For emergencies, contact the National Poison Control Center at 1-800-222-1222. For pesticide information, contact the National Pesticide Information Center (NPIC) at 1-800-858-7378 or on-line at http://npic.orst.edu/. Also, when requested by your customer or other concerned individuals, be prepared to provide the trade and common names of the pesticides and copies of the product labels and MSDS.

\section{Your Professional Image}

It takes work to achieve and maintain a professional image. As a representative of your pest management company, seek to reinforce a positive company image (Figure 4). Remember, your work actions reflect on your company and on the entire pest management industry. Be sure to leave a positive impression. 


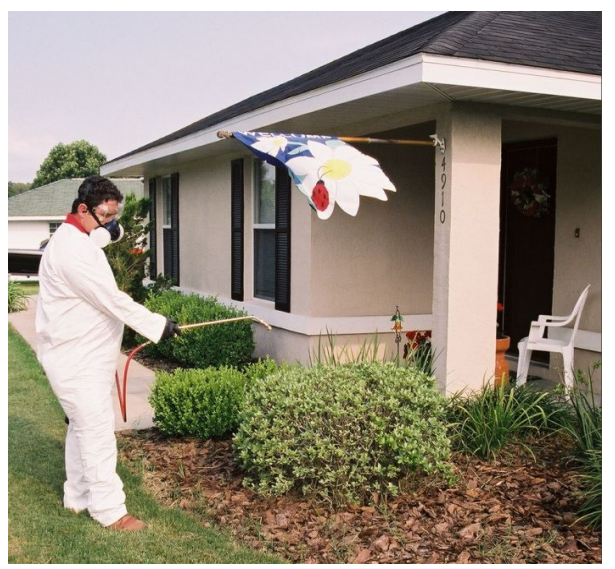

Figure 4. Professional image reflects positively upon your company.

\section{Additional Information}

Aerts, M.J., O.N. Nesheim, and F.M. Fishel. 1998. Pesticide Recordkeeping. EDIS Publication PI-20, http://edis.ifas.ufl.edu/PI012 (viewed May, 2008). Department of Agronomy, IFAS, University of Florida, Gainesville, FL.

Fishel, F.M. 2005. Enhancing the Effectiveness of a Professional Pest Management Program. EDIS Publication PI-39, http://edis.ifas.ufl.edu/PI076 (viewed May, 2008). Department of Agronomy, IFAS, University of Florida, Gainesville, FL.

Fishel, F.M. 2005. Selecting a Professional Pest Control Service. UF/IFAS EDIS Document PI-38. http://edis.ifas.ufl.edu/PI075 (viewed May, 2008). Department of Agronomy, IFAS, University of Florida, Gainesville, FL.

Nesheim, O.N. 1998. Registry of Persons Requiring Prior Notification of the Application of Pesticides. EDIS Publication PI-5, http://edis.ifas.ufl.edu/PI004 (viewed May, 2008). Department of Agronomy, IFAS, University of Florida, Gainesville, FL. 